\title{
Job Features, Job Values and Affective Strength
}

\author{
Peter Warr, Institute of Work Psychology, University of Sheffield, \\ Ilke Inceoglu, Surrey Business School, University of Surrey
}

\begin{abstract}
Job values and job characteristics are widely assumed to interact with each other, in that jobholders' preferences are thought to moderate associations of job content with well-being. However an examination of previous research revealed considerable between-feature inconsistency in findings about moderation, and a new contingency variable was introduced to account for that inconsistency. This construct, labelled "affective strength", was defined and investigated through the spread of a feature's desirability in a studied sample. A threesample examination of feature-by-value interactions across a broad set of job features confirmed that moderation by job values is often weak and that patterns vary between features. As predicted, associations between job characteristics and well-being were found to be significantly more influenced by worker preference when those characteristics were of lower affective strength - having greater variance in desirability. Models of job design need to incorporate worker preferences but also the varying influence of those preferences - in effect through a second-order interaction.
\end{abstract}

In reviewing the "person-situation controversy", Pervin (1989) pointed to a general agreement that "most psychologists now see themselves as interactionists" (p. 350) accepting that both the person and the environment affect people's experience and behaviour. However, as he argued, "interaction" has several meanings and we need to learn more about different forms of operation. For example, does the combined operation of personal and situational factors always involve a statistical interaction? Or are associations with personal and situational variables sometimes independent of each other? In the latter case, what variables might underlie the difference between patterns?

Applying Pervin's profession-wide account to the specific area of organizational research, work and organizational psychologists typically see themselves as interactionists. This is exemplified in the widespread acceptance of conclusions drawn by Hackman and Lawler (1971) and Hackman and Oldham (1980) about the notion of "growth-need strength". Within their model of job characteristics and psychological outcomes, these authors proposed a moderating influence from workers' preference for a compound of intrinsic job features how much they would like to have that compound set of features in a job. They found that the correlation of intrinsic characteristics with job-related well-being tended to be greater for workers whose preference for the set of features (their "growth-need strength" or "GNS") 
was high rather than low. Other investigations have reported similar findings: correlations between selected intrinsic job features and job satisfaction are on average greater for individuals with higher growth-need strength (e.g., Loher, Noe, Moeller, \& Fitzgerald, 1985).

However, data-analyses in these early studies were restricted to simple comparisons between average feature-satisfaction correlations of high-GNS versus low-GNS workers, and tests of statistical significance were not reported. Although reported correlation patterns do suggest a general trend as proposed, the statistical evidence does not meet standards now expected in the profession. Furthermore, for some combinations of personal values and job characteristics the moderating trend was absent or very small. This recurrent inconsistency in GNS results was noted in passing by the original investigators (Hackman \& Lawler, 1971, p. 278), but appears not to have been considered since.

Growth-need strength is one form of job-related "value". That construct has been defined as "a broad preference for one state of affairs over others" (Hofstede, 1984, p. 389), "a conception of the desirable" (Schwartz, 1999, p. 24), "that which one acts to gain and/or keep" (Locke, 1976, p. 1304), and people's "preferences and aversions, their likes and dislikes" (Mischel, 1977, p.345). Values embody positive or negative evaluations and desires, and can range in scope from broad ideologies and world-views to specific preferences for single objects or ideas. They have been examined, for instance, through research into personal and vocational interests, attitudes, orientations, stereotypes, prejudices, and in terms of job-feature preferences (e.g., Konrad, Ritchie, Lieb, \& Corrigall, 2000).

Although the studies of growth-need strength cited above examined the GNS construct in terms of the degree to which workers wanted specified characteristics, other investigations instead asked about the studied characteristics' perceived importance (e.g., Jackson, Paul, \& Wall, 1981; Sims \& Szilagyi, 1976). Research into job-related values (e.g., van den Broeck, van Ruysseveldt, Smulders, \& De Witte, 2011) and broader theories and investigations of values have also focused on personal importance. For example, the World Values Survey (www.worldvaluessurvey.org; Warr, 2008), the European Values Study (www.europeanvaluesstudy.eu) and the Schwartz Values Scale (Schwartz, 1992) ask directly for ratings of importance. In organizational research, values have similarly been indexed as perceived importance by, for example, Bipp (2010) and Gorgievski, Ascalon and Stephan (2011). The two types of measure, importance ratings and recorded wants, are logically interdependent: people want elements that are important to them, and the nature of personally-important features ensures that they are wanted. The two value assessments are thus likely to be intercorrelated as largely equivalent, but empirical comparisons appear to be lacking.

Other organizational studies have extended the GNS work into different measures of intrinsic value orientation. In only a proportion of cases is it found that those orientations significantly moderate the association between a job feature and well-being (e.g., de Jonge, van der Velde, \& Jansen, 2001; Tiegs, Tetrick, \& Fried, 1992; van den Broeck et al., 2011; Viswesvaran, Sanchez, \& Fisher, 1998). Furthermore, another kind of investigation - of satisfaction as a function of single job features - also yields inconsistent findings about the occurrence of moderation by values. Rice, McFarlin, and Bennett (1989) and Rice, Gentile, and McFarlin (1991) investigated job satisfaction as a joint function of single job features (pay, opportunity to learn new skills, etc.) and workers' preference for a feature, measured either by level of want or perceived importance. Although the expected feature-preference interaction was found in some cases, it was absent for about a third of the characteristics 
studied. Rice et al. (1991, p. 38) could offer "neither a conceptual nor a statistical explanation" for this less-than-universal occurrence of the interactive pattern.

Three forms of research (studies of GNS, value orientation, and single-feature preference) have thus cast doubt on claims for the universal presence of statistical moderation by values, whether measured in terms of want or personal importance. As in other cases of inconsistent findings, we need to define and examine possible contingency factors. Considering social behaviour in general, Mischel (e.g., 1977) introduced the notion of "situational strength". Arguing that environmental variables matter more when they are "strong" and personal variables have greater influence when situational characteristics are "weak", he defined strength in terms of two cognitive outcomes. Strong situations are "powerful to the degree that they lead everyone to construe the particular events in the same way" and "induce uniform expectancies regarding the most appropriate response pattern" (Mischel, 1977, p. 347). On the other hand, weak situations lead to more varied perceptions and potential behaviours, so that "individual differences would be expected to exert the greatest influence in the weak (high-variation) situations and to have the smallest effect in the powerful (low-variation) ones" (Mischel, 1977, p.348).

This framework has been widely accepted by researchers in many areas, although empirical support has largely derived from laboratory investigations and many findings have not been positive (Cooper \& Withey, 2009; Meyer, Dalal, \& Hermida, 2010). Mischel's definitional emphasis was on consensus versus variability in perceptions, but his construct of strength has since been measured in very different ways - through "a host of ad hoc operationalizations" (Meyer et al., 2010, p. 122). Most common is the average level of an environmental feature rather than its variance.

For example, in an organizational setting Barrick and Mount (1993) focused on the level of personal autonomy available to a worker. They showed that a proportion of personality traits (three of the five studied) were more linked to job performance in tasks which impose fewer specific demands and permit more autonomy (viewed as "weak" situations) than when autonomy was less (considered to represent a "strong" situation, with unambiguous implications for required behaviours). A similar investigation by Gellatly and Irving (2001) focused on job performance of a contextual kind, again finding a significant interaction between personality and autonomy in some but not all cases (for two of the three traits examined). Parallel research has compared job behaviours which are either more discretionary or less discretionary. Behaviours arising from discretion and personal choice were found to be more associated with workers' affect than were behaviours constrained by discretion-limiting job requirements (Warr, Bindl, Parker, \& Inceoglu, 2013).

It is notable that Mischel's construct of situational strength has rarely been examined in terms of its original characterization - between-person spread of an environmental score. However, an index of that kind has been applied by researchers into the perceived climate of organizations. In a study across bank branches, Schneider, Salvaggio and Subirats (2002) assessed climate strength in terms of (low) standard deviation in perceptions of customer service. They found that dimensions of service climate with a smaller standard deviation (i.e., the "stronger" ones) were more predictive of customer satisfaction than were those with a wider spread of scores.

\footnotetext{
${ }^{1}$ Mischel (1977) explicitly viewed "situation" and "environment" as equivalent terms. He sought a general model of the interaction of aspects of the environment (outside the person) with aspects within the person.
} 
Investigations of situational strength have looked at the environment in terms only of its perceived objective nature; for instance, Mischel (1977) cited a red traffic light as a typical strong situation and a projective-test stimulus as a weak one. Environmental strength has thus been conceptualized in terms of observable content. "Content strength" (as it may be termed) is clearly important, but this exclusive focus has prevented consideration of another aspect of environmental features which has particular relevance to well-being. This second form of strength concerns evaluative tone, and may be termed "affective strength".

All perceptions of the world are to some degree suffused with positive or negative evaluation - assessments in some form of "good" versus "bad" (e.g., Osgood, Suci \& Tannenbaum, 1957). Whereas the previously-studied situational strength in terms of content refers to observable features, the associated notion of strength which is affective primarily concerns the feeling that is implied by content. Given that feeling provides the core of wellbeing in all its forms and is inherent in all perception, affective strength clearly deserves attention in the area of this paper.

Extending Mischel's framework, the affective strength of an environmental feature is expected to influence that feature's importance for well-being relative to the contribution from variables within the person. For instance, a stimulus that generates feelings of intense pain or extreme delight is likely to have a clear and similar impact on everyone, having considerable affective strength and overwhelming the influence of personal characteristics. On the other hand, an input from the environment which allows a range of different evaluations (i.e., is of low affective strength) is expected to permit more impact from personal variables. Job-by-value interactions are thus predicted to be weaker for job features which have greater affective strength.

A further needed refinement to earlier publications concerns type of measurement. Situational strength in terms of content has usually been investigated as the mean level of responses (see above) rather than through Mischel's original specification in terms of variability. It is important instead to examine strength of an affective kind in the way proposed by Michel. Following Schmidt and Hunter (1989) and Schneider et al. (2002), affective strength in terms of spread will be indexed here as the standard deviation of a job feature's desirability in an entire sample. To aid comparison with previous organizational studies, this primary index will be accompanied by conventional but less appropriate scoring in terms of mean level. The two forms will be abbreviated here as Affective Strength SD (in terms of the standard deviation of a feature's sample-level desirability, as in Mischel's original model) and Affective Strength $M$ (in terms of the mean level of a feature, as in organizational studies illustrated earlier). The following hypotheses will be examined:

Hypothesis 1 The magnitude of moderation by job-related value is a significant inverse function of features' Affective Strength SD, in that stronger moderation-by-value of associations between job features and well-being occurs for weaker features - the ones with greater between-person variance in desirability scores.

Hypothesis 2 The magnitude of moderation by job-related value is a significant inverse function of features' Affective Strength $M$, in that stronger moderation-by-value of associations between job features and well-being occurs for weaker features - the ones that are on average desirable to a moderate rather than extreme degree.

Note that these hypotheses are explicitly non-causal. They seek to obtain needed information about not-known empirical patterns rather than aiming to test a causal model. 
Although findings may provide a basis for subsequent causal enquiry, the current research requirement is different - to identify the nature of interactive relationships, the "what" rather than the "why" of psychological processes.

\section{METHOD}

Three investigations were conducted through an international web-site advising individuals without charge about assessment procedures for staff recruitment and development. On-line questionnaires were completed by workers in a range of organizations in several countries, and analyses were restricted to those who reported that English was their first language. The issues of this paper were examined through identical instruments in the three studies.

\section{Samples}

In Study 1, 51\% of the 1001 respondents were male and $42 \%$ were in supervisory or managerial roles. The sample (with an average age of 35) came mainly from the United Kingdom (61\%), Australia (13\%), New Zealand (5\%) and India (4\%), and most (61\%) had university-level qualifications. Employment sectors included retail, education, health services, manufacturing and public administration, with eight percent of jobs in each of sales, in human resources and in operations and $13 \%$ described as general management.

In Study $2(N=840), 53 \%$ of participants were male and the sample's average age was again 35. Principal countries of residence were United Kingdom (48\%), Australia $(21 \%)$, New Zealand (6\%) and USA (5\%). Sixty-four percent held a university or college degree, $32 \%$ were managers, and nine percent were supervisors or team leaders. Most common business sectors were finance, banking, retail, aviation and manufacturing, and nine percent of respondents were employed in the public sector ${ }^{2}$.

The sample in Study $3(N=4217)$ came mainly from the United Kingdom $(69 \%)$, Australia (16\%) and New Zealand (6\%). The average age was 39 years, $51 \%$ were male, and $49 \%$ were in supervisory or managerial roles. Two-thirds held a university or college degree, and the most common employment sectors were retail, financial services, public administration, education, and manufacturing.

\section{Instruments}

Job content and job-related values were investigated through the same 33 job characteristics. These extended across the broad range of elements which have been identified as important for well-being by researchers in many settings (e.g., Warr, 2007, 2013). For each characteristic, a worker rated the amount present in his or her job (its perceived actual level) and also his or her evaluation of the feature (its wanted level). In each case, actual job features (AJF) and wanted job features (WJF) were examined through the same two descriptive items derived from pre-test studies. Responses to the two items were subsequently averaged for each feature in respect of AJF and WJF separately.

For the measurement of a wanted job feature (WJF) participants reported how much of that feature they would like in their ideal job. For example, "In your ideal job, how much opportunity would you have to try out new ideas or procedures?" and "In your ideal job, how much responsibility would you have for a team or larger unit?". Subsequently they rated for

\footnotetext{
2 A different issue from Study 2 has been described by Warr and Inceoglu (2012). There is no overlap in the hypotheses and themes examined in the two papers.
} 
the same items how much of each was present in their current job - the perceived level of an actual job feature (AJF). In Studies 2 and 3 all WJF items were presented first, prior to the set of all AJF items; and in Study 1 WJF and AJF ratings (in that sequence) were paired for each job feature, so that workers rated one feature's desired and actual levels before considering another feature. For both wanted and actual levels the same nine response options were provided. Scored from 1 to 9, these ranged from "None at all" to "The most possible".

In order to aid presentation by providing summary indicators of key job components, the 33 features were submitted to principal axis factoring of WJF values with promax rotation and Kaiser normalization (Warr \& Inceoglu, 2012). Eigen values and scree patterns pointed to the following eight intercorrelated factors.

1. Supportive environment: Eight job features covering physical and social supports such as a comfortable workplace, job security, feedback about performance, and supportive colleagues (alpha coefficients in Studies 1, 2 and 3 respectively: WJF .88, .90 and .90; AJF .88, .91 and $.90)$.

2. Competition and financial focus: Four features such as working in a competitive market, focusing on financial outcomes, and competing with other people (alpha coefficients: WJF $.90, .89$ and .87 ; AJF .90, .89 and .87).

3. Personal influence: Four job features including the chance to organize your own activities, the opportunity to express your views, and having influence on the organization (alpha coefficients: WJF .88, .87 and .87; AJF .91, .91 and .90).

4. Challenging workload: Five features such as very demanding goals, a lot of work to do, and long hours (alpha coefficients: WJF .85, .87 and .85; AJF .88, .90 and .88).

5. Ethical principles: Four features covering consistency with personal values, concern for social responsibility, and contribution to society (alpha coefficients: WJF .84, .85 and .85 ; AJF .85, .86 and .86).

6. Career progress: Four features including prospects for promotion or other career moves, personal development, and taking a variety of roles (alpha coefficients: WJF .89, .90 and .91; AJF .97, .93 and .92).

7. Amount of social contact: Two features involving frequency of interaction with others and number of social contacts (alpha coefficients: WJF .85, .84 and .82; AJF .78, .79 and .83; correlations between the two component features: WJF .67, .66, .64; AJF .59, .55, .66).

Note that this factor concerns the quantity of social contact; the quality of contact is included within supportive environment in Factor 1.

8. Status and responsibility: Two features covering a high-status position and responsibility for a team or larger unit (alpha coefficients: WJF .80, .81 and .78; AJF .85, .87 and .86; correlations between the two component features: WJF .52, .51, .49; AJF .67, .67, .65).

These eight factors provide a statistically appropriate summary of the studied job features, differentiating these in conceptually meaningful terms which are well established in previous job design research. The factors are not claimed as a general model of job content, but are used here to summarize and aid reporting of the broad set of 33 investigated features. 
Participants described their job-related well-being in two commonly-studied respects, job engagement and overall job satisfaction. Those are conceptually and empirically associated with each other, but they have a contrasting motivational emphasis. "Engagement connotes activation, whereas satisfaction connotes satiation" (Macey \& Schneider, 2008, p. 8); "it is the sense of energy and enthusiasm in engagement that makes the construct different" from satisfaction (Macey \& Schneider, 2008, p. 24). The two forms of well-being thus differ in terms of activation within the affective circumplex described by Russell (2003) and others, but they are of course similar in that both represent positive rather than negative sectors of that framework.

Job engagement was measured through a six-item scale linked to proposals by Kahn (1990), Schaufeli, Bakker, and Salanova (2006) and others, consistent with the "growing consensus" identified by Bakker, Albrecht, and Leiter (2011, p. 22) that the construct can be defined in terms of high energy and high involvement in a job (Inceoglu \& Fleck, 2010; Inceoglu \& Warr, 2011). The scale thus emphasized energy and absorption. Three items each covered job-related energy (for instance, "My job makes me feel energized") and job absorption (e.g., "I get carried away by what I'm working on"). The alpha coefficient was $.91, .89$ and .93 in Studies 1, 2 and 3 respectively. Evidence about content, construct and criterion-related validity of this scale has been presented by Inceoglu and Fleck (2010) and Ungemah (2010).

Overall job satisfaction has been measured in a variety of different ways, often with a range of items extending beyond the focal construct itself - a relatively passive acceptance of an adequate ("satisfactory") situation (Warr \& Inceoglu, 2012). Valid measurement of satisfaction requires targeted assessment of that construct alone rather than also including items with a more diverse content. Participants in this study therefore responded to the specific question "Overall how satisfied or dissatisfied are you with your job?" with seven options from extremely dissatisfied to extremely satisfied. Assessments of this directlytargeted kind are highly correlated with multi-item indicators of satisfaction (Wanous, Reichers, \& Hudy, 1997). In Studies 1, 2 and 3 respectively, the two forms of well-being were intercorrelated .50, .56 and .68. This overlap (also found by Rich, Lepine, and Crawford, 2010, and others) is of course expected from the common centrality of positive affect.

\section{Analyses}

Patterns of moderation were examined at two levels - for all 33 job features and in respect of the summarizing eight factors. At both levels, interactions between a job characteristic and a corresponding job value were examined in two ways. First, following the descriptive convention adopted by early job design researchers (above) comparisons were made for each factor-outcome correlation between workers with different strengths of want. Separately for each of the 33 job features and the eight job factors, respondents were divided into one-third sub-samples of low, medium and high levels of the linked value (WJF), and job-outcome correlations were computed for each sub-sample. This simple form of analysis was reported in all early publications in this area, and is repeated here for comparison with those findings.

However, detailed investigation requires more sophisticated computations and the paper's hypotheses were tested through a second form of analysis. For each job feature or factor, following standardization of scores the AJF-times-WJF interaction term was introduced as the second step of a multiple regression analysis of workers' responses in addition to AJF and WJF alone. Correlations were then computed across the sampled job 
characteristics between the magnitude of a characteristic's AJF-times-WJF interaction and each form of affective strength. These analyses were undertaken separately for the 33 job features and for their eight factors as described above. Interaction magnitude was indexed in the conventional manner as the $R$-squared increment from adding the AJF-WJF crossproduct.

Hypothesis 1 concerns the paper's derivation from Mischel's original specification, here labelled as Affective Strength SD - the population-level spread of desirability of a characteristic. It proposes that a linked value is more important in interaction when that aspect of the environment is of lower affective strength, defined in terms of a larger standard deviation of want. The parallel Hypothesis 2, in respect of Affective Strength M, was similarly examined through WJF scores from an entire sample, in that case in terms of a job feature's mean desirability level, expecting negative associations across job characteristics between mean desirability and the magnitude of AJF-WJF interactions ${ }^{3}$.

\section{RESULTS}

Table 1 shows the perceived actual level and the wanted level of each of the summarizing job factors. Linked to the studies' generally desirable job content, workers wanted higher levels in each respect; the final row of the table presents overall average scores with medians of 5.41 and 6.81 for AJF and WJF respectively. Wanted and actual mean scores were each similar between Studies 2 and 3, but Study 1 had substantially higher WJF responses (an overall mean of 6.95 versus 6.81 and 6.73 in the other studies) and slightly lower AJF scores (overall mean of 5.36 versus 5.41 and 5.45).

The procedure in Study 1 was identical to that of the other studies with one exception. As described in the Method section, reports of wanted and actual levels of each feature were in that case provided in immediate (paired) succession for each feature singly, whereas in the other investigations the complete set of all WJF ratings was obtained before AJF was introduced. It appears that bringing together a person's WJF and AJF judgments about a feature in Study 1 may have focused attention on that particular characteristic and primed the person to emphasize more strongly the apparent deficiencies of AJF levels and an associated desire for those levels to be increased. As a result (shown in Table 1) workers in Study 1 reported that they desired levels of many features which exceeded the wanted levels reported in the other two studies.

Overall patterns of moderation for the eight summarizing factors are shown descriptively in Table 2, and separate findings from each study are in the Appendix. It can be seen that correlations between a job factor and well-being tended in general to be greater for workers who more value that factor. In respect of job satisfaction, the bottom row of Table 2 shows overall mean factor-outcome correlations of 0.32 and 0.51 for low-want and high-want workers respectively; for job engagement those overall means were 0.32 and 0.46 . However, despite this general tendency statistically significant interactions were infrequent, occurring in only around a third of the cases.

\footnotetext{
${ }^{3}$ It could be argued that these desirability indexes are not entirely independent of an individual worker, since that worker's own score is included in full-sample analyses. However, the present large sample sizes imply that any one person's score has only a trivial impact on an overall pattern. Furthermore, analyses in each study which instead applied desirability indexes from the paper's other studies yielded identical patterns. That consistency is linked to the fact that average WJF scores were almost perfectly intercorrelated between the three investigations; for the 33 job features that average $r$ across the three studies was 0.95 .
} 
Table 2 also illustrates some differences between the eight job aspects. For example, in all three studies the presence or absence in a job of competition and financial focus (Factor 2) was more strongly linked to well-being among workers who more valued a competitive environment than for low WJF scorers. Table 2 reports average correlations of that job factor with job satisfaction of .37 versus .06 for the high- versus low-WJF sub-groups, and consistent findings from each study are shown in the Appendix. On the other hand, Factor 1 (generally supportive job conditions) was associated with job-related well-being to a similar degree irrespective of a person's preference, yielding average correlations with job satisfaction of .53 and .42 for those with stronger and weaker preferences for environmental support.

Hypotheses 1 and 2 offered a possible explanation of this between-characteristic variability - that the magnitude of moderation by value would be an inverse function of an environmental feature's affective strength. As described in the Method section, the samplelevel desirability of each job feature was measured in two ways - primarily as its standard deviation (Affective Strength SD, reflecting Mischel's perspective) and also as its average wanted level (Affective Strength $M$, as in previous organizational research). All the job characteristics examined here were to some degree desirable rather than undesirable, so that respectively positive and negative correlations are expected between value-moderation and job characteristics' affective strength measured as the standard deviation or the mean. The two columns identified as (1) in Table 3 report findings in respect of the 33 features, and the columns labelled (2) contain results for the eight summarizing job factors.

In support of Hypothesis 1, Table 3 shows that average correlations across job characteristics between moderation by value ( $R$-squared increment) and the sample-level standard deviation of a characteristic (Affective Strength SD) were $.55(N=33$ features) and .59 ( $N=8$ factors) for job satisfaction and .55 and .65 for job engagement. Job-related values are significantly stronger moderators of the correlation between job characteristics and wellbeing when characteristics have a greater evaluative standard deviation. Thus, for example, the factor Competition and Financial Focus had the largest WJF standard deviation (mean = 1.41), and relationships of this factor with well-being were significantly moderated by the linked value in all three studies (see Table 2). On the other hand, correlations with Supportive Environment (Factor 1, with a small average s.d. of .96) were in no case influenced by WJF.

In respect of Hypothesis 2, examining Affective Strength M, average desirabilitymoderation correlations across the three studies for job satisfaction were -.73 $(N=33$ features) and -.85 ( $N=8$ factors), and for job engagement these correlations were - .66 and .74. As predicted by the second hypothesis, interactions between actual and preferred levels were significantly greater for job features which tend towards the middle of the WJF range for an entire sample rather than being of more extreme desirability.

Parallel analyses in terms of the two measurement perspectives, Affective Strength SD and Affective Strength M, thus provide parallel support for the paper's framework. This similarity of findings is linked to a strong statistical overlap between the two indicators of strength. In Studies 1, 2 and 3 respectively, intercorrelations between a sample's mean and standard deviation were -.72, -.72 and -.83 (mean -.76) for the 33 features, and -.71, -.61 and .51 (mean -.61) for the eight factors.

\section{DISCUSSION}


This research has advanced understanding of a compound-variable issue which is of widespread and substantial importance in many areas of psychology - what factors influence the presence or absence of statistical interaction between persons and situations? The paper goes beyond previous publications in four respects: extending Mischel's (e.g., 1977) situational strength construct to research into job-related well-being; introducing and investigating a new form of that original construct; proposing a model to account for variability in previous findings about job-by-value interaction and testing this in a novel way; and demonstrating the replicability of patterns across three independent samples with an unusually comprehensive range of job characteristics.

The paper's two hypotheses about moderation by affective strength were supported. Aspects of a job which have more limited value-variance or are more extremely desirable for an entire sample are linked to well-being in a more standard manner, with less influence from personal preferences, than are job characteristics of low affective strength. For low affectivestrength characteristics, individual differences in preference more strongly contribute to the association between job content and well-being. Previous research into the alternative content-based notion of situational strength (described earlier) has strayed from Mischel's definition as the spread of perceived content. Studies in organizations have instead emphasised measures of average level, for instance of available autonomy. By analysing affective strength in terms of WJF standard deviation, this research has confirmed for the first time in the area of well-being the moderating importance of variability as envisaged by Mischel.

We need now to step back and seek to understand the source of differences in evaluative variability between different features. Why is one job feature similarly evaluated across a population, whereas another feature has a larger WJF standard deviation? It seems likely that between-person large or small spread of preferences is linked to a feature's low or high contribution to a need that is "basic". General models of basic needs, extremely important in earlier decades, are currently out of fashion, but it remains clear that human functioning derives from primary energisers of some kind. For example, Alderfer (1972) emphasised needs for Existence, Relatedness and Growth, and Self-Determination Theory is built on Competence, Autonomy and Relatedness (e.g., Gagné \& Deci, 2005).

Do some job features of the kind studied here contribute more than others to the attainment of basic needs, reflecting that motivational universality through a smaller variance in evaluation? For example, the present low-variance factor of Supportive Environment (including scales about, for instance, safe working conditions and support from other people) could be viewed as important for Alderfer's basic needs for Existence and Relatedness, whereas Competition and Financial Focus (Factor 2), with the largest WJF standard deviation here, is not essential in basic need terms.

The present studies point to another issue which bears upon many psychological models but is rarely considered. Mischel and others have discussed the construct of situational strength in entirely psychological terms - its inherent nature and likely implications for mental and behavioural processes. Those psychological discussions are fundamental to understanding and the creation of process models, but the issue might also be viewed in terms of statistical relationships. Given that a smaller standard deviation (as in Mischel's definition of strength) reduces the likelihood of a statistical interaction with other measured variables (e.g., Aquinas, 1995), one could interpret findings about strength-asvariability as a reflection of statistical characteristics. 
Psychological and statistical interpretations can thus exist in parallel with each other; a psychological model, postulating mental processes which underlie other observations, can be accompanied by parallel statistical patterns. The two perspectives are mutually supporting and often logically interdependent, and overlap between them does not detract from the value of either. Mischel's theory and the derived model introduced here concern underlying psychological processes, and are no less valuable because of an accompanying statistical pattern; conversely, the value of a statistical analysis is not undermined by Mischel's model. Reality can be viewed in more than one way.

\section{Research implications}

There is a general need for additional evidence about the operation of content strength and affective strength in work situations. Meyer et al. (2010) point out that much of the widelycited research has been in a laboratory setting, perhaps using scenarios and expected rather than actual responses; and Cooper and Withey (2009) conclude from their review that the "transformation from hypothesis to dogma is based more on the plausibility of the [situational strength] hypothesis and sheer repetition than on any empirical evidence" (p.64).

In respect specifically of research into well-being, it is important to replicate and extend the present findings about affective strength. For example, the present job features were all to some extent desirable, and research needs to check also the varying pattern of moderation by affective strength for characteristics which are stressful or otherwise undesirable. The present pattern of differential moderation by affective strength was seen to extend across two positive aspects of job-related well-being, and it is likely to be found also for job-related strain and for context-free well-being (global happiness, life satisfaction, etc.), but these and similar possibilities have yet to be examined. The general point is that we need in these ways sometimes to introduce another variable as in a second-order interaction.

Values are central components of many broader constructs examined by psychologists, and extension of the present contingency pattern to other individual-difference variables requires consideration. For example, traits of personality can be viewed within the present framework, since traits strongly reflect individuals' preferences, desires and values. Some evidence is available that certain narrowly-defined traits moderate the association between particular job features and well-being. Kahn, Wolfe, Quinn, and Snoek (1964) and Keenan and McBain (1979) showed that the correlation of role ambiguity with well-being differed between workers with low and high ambiguity-tolerance. Vroom's (1959) study found that the autonomy-satisfaction correlation depended on a worker's low authoritarianism and high preference for independence. Other job-related instances of personality moderation have been reported by Dijkstra, van Dierendonck, Evers, and de Dreu (2005), Rogelberg, Leach, Warr, and Burnfield (2006), Bond, Flaxman, and Bunce (2008), and Rego, Souto, and Cunha (2009).

It is now desirable to develop research of that kind along the lines of the present investigations. What are the value-based components of each personality trait which give rise to that trait's moderation or otherwise of an association between a job characteristic and wellbeing? Specific value preferences of the kind studied here may be at least partly responsible for personality-moderated patterns of feature-outcome relationships. However, it is clear that moderation of job-outcome association by personality does not always occur (e.g., Morris \& Snyder, 1979), and it is important to identify reasons for this variability. The present findings about affective strength imply that associations between environmental features and aspects of well-being are likely to be moderated by certain personality traits primarily when a studied 
aspect of the environment has a greater spread of evaluation. This general combinatorial possibility now requires investigation. Other forms of person-situation interaction are likely also to depend on the operation of relevant values. For example, individuals with different values select themselves differentially into situations (including jobs) which have different features, and research is now needed into the moderating role of specific values in a particular transition.

\section{Practical implications}

The present findings imply that job design procedures and management policies need to focus on job values, but only those of a particular, specifiable kind. Decisions need not be shaped by individual-difference considerations in respect of extremely desirable (and presumably extremely undesirable) aspects of the job. For those, it remains true that "one size fits all" across a group. However, many job features are on average of non-uniform desirability, and for these it is essential that organizations recognize and act upon variation between their workers if satisfaction and engagement are to be maximized and staff turnover is to be reduced. For aspects of a job with low affective strength, different preferences should be considered both in designing that job and in selecting and promoting workers to undertake it.

Thus, when envisaging alternative job designs or selection frameworks, the environmental characteristics which require a differentiated approach are those which are varyingly desirable between workers, such as competition and financial focus in the current Factor 2. On the other hand (for example) a supportive supervisor and other features in the current Factor 1 are likely to be more universally linked with well-being. In all cases, a needed first step is to identify a job's key features and define likely reactions to those, ranging from characteristics similarly evaluated by everyone to those with diverse personal preferences. From that starting-point, staff selection and promotion procedures, as well as programmes of induction or career-planning, need to supplement their conventional emphasis on required skills by additionally considering preferences and their associated motivational styles in the required cases.

In addition, the present findings point to a superordinate requirement - for the training of managers in psychological constructs and the application of those constructs in more effective management. For example, it is still unusual for managers to view employee motivation in terms of the features of a job. A general shift in thinking is required for managers most effectively to increase well-being, motivation and performance.

\section{REFERENCES}

Alderfer, C. P. (1972). Existence, Relatedness, and Growth: Human Needs in Organizational Settings. New York: The Free Press.

Aquinas, H. (1995). Statistical power problems with moderated regression in management research. Journal of Management, 21, 1141-1158.

Bakker, A. B., Albrecht, S. L., \& Leiter, M. P. (2011). Key questions regarding work engagement. European Journal of Work and Organizational Psychology, 20, 4-28.

Barrick, M. R., \& Mount, M. K. (1993). Autonomy as a moderator of the relationships between the Big Five personality dimensions and job performance. Journal of Applied Psychology, 78,111-118. 
Bipp, T. (2010). What do people want from their jobs? The Big Five, core self-evaluations and work motivation. International Journal of Selection and Assessment, 18, 28-39.

Bond, F. W., Flaxman, P. E., \& Bunce, D. (2008). The influence of psychological flexibility on work redesign: Mediated moderation of a work reorganization intervention. Journal of Applied Psychology, 93, 645-654.

Cooper, W. H., \& Withey, M. J. (2009). The strong situation hypothesis. Personality and Social Psychology Review, 13, 62-72.

De Jonge, R. D., van der Velde, M. E. G., \& Jansen P. G. W. (2001). Openness to experience and growth need strength as moderators between job characteristics and satisfaction. International Journal of Selection and Assessment, 9, 350-356.

Dijkstra, M. T. M., van Dierondonck, D., Evers, A., \& de Drew, C. K. W. (2005). Conflict and well-being at work: The moderating role of personality. Journal of Managerial Psychology, 20, 87-104.

Gagné, M., \& Deci, E. L. (2005). Self-determination theory and work motivation. Journal of Organizational Behavior, 26, 331-362.

Gellatly, I. R., \& Irving, P. G. (2001). Personality, autonomy, and contextual performance of managers. Human Performance, 14, 231-245.

Gorgievski, M. J., Ascalon, M. E., \& Stephan, U. (2011). Small business owners' success criteria, a values approach to personal differences. Journal of Small Business Management, 49, 207-232.

Hackman, J. R., \& Lawler, E. E. (1971). Employee reactions to job characteristics. Journal of Applied Psychology, 55, 259-286.

Hackman, J. R., \& Oldham, G. R. (1980). Work redesign. Reading, MA: Addison-Wesley.

Hofstede, G. (1984). The cultural relativity of the quality of life concept. Academy of Management Review, 9, 389-398.

Inceoglu, I., \& Fleck, S. (2010). Engagement as a motivational construct. In S. Albrecht (Ed.) The handbook of employee engagement: Models, measures and practices (pp. 74-86). Cheltenham UK: Elgar.

Inceoglu, I., \& Warr, P. B. (2011). Personality and job engagement. Journal of Personnel Psychology, 10, 177-181.

Jackson, P. R., Paul, L., \& Wall, T. D. (1981). Individual differences as moderators of reactions to job characteristics. Journal of Occupational Psychology, 54, 1-8.

Kahn, R. L., Wolfe, D. M., Quinn, R. P., \& Snoek, J. D. (1964). Organizational stress: Studies in role conflict and ambiguity. New York: Wiley.

Kahn, W. A. (1990). Psychological conditions of personal engagement and disengagement at work. Academy of Management Journal, 33, 692-724. 
Keenan, A., \& McBain, G. D. M. (1979). Effects of type A behaviour, intolerance of ambiguity, and locus of control on the relationship between role stress and workrelated outcomes. Journal of Occupational Psychology, 52, 277-285.

Konrad, A. M., Ritchie, J. E., Lieb, P., \& Corrigall, E. (2000). Sex differences and similarities in job attribute preferences: A meta-analysis. Psychological Bulletin, 126, 593-641.

Locke, E. A. (1976). The nature and causes of job satisfaction. In M. D. Dunnette (ed.), Handbook of industrial and organizational psychology (pp. 1297-1343). Chicago: Rand McNally.

Loher, B. T., Noe, R. A., Moeller, N. L., \& Fitzgerald, M. P. (1985). A meta-analysis of the relation of job characteristics to job satisfaction. Journal of Applied Psychology, 70, 280-289.

Macey, W. H., \& Schneider, B. (2008). The meaning of employee engagement. Industrial and Organizational Psychology, 1, 3-30.

Meyer, R. T., Dalal, R. S., \& Hermida, R. (2010). A review and synthesis of situational strength in the organizational sciences. Journal of Management, 36, 121-140.

Mischel, W. (1977). The interaction of person and situation. In D. Magnusson \& N. S. Endler (Eds.), Personality at the cross-roads: Current issues in interactional psychology (pp. 333-352). Hillsdale, NJ: Lawrence Erlbaum.

Morris, J. H., \& Snyder, R. A. (1979). A second look at need for achievement and need for autonomy as moderators of role perception-outcome relationships. Journal of Applied Psychology, 64, 173-178.

Osgood, C. E., Suci, G. J., \& Tannenbaum, P. H. (1957). The measurement of meaning. Urbana, Illinois: University of Illinois Press.

Pervin, L. A. (1989). Persons, situations, interactions: The history of a controversy and a discussion of theoretical models. Academy of Management Review, 14, 350-360.

Rego, A., Souto, S., \& Cunha, M. P. (2009). Does the need to belong moderate the relationship between perceptions of spirit of camaraderie and employees' happiness? Journal of Occupational Health Psychology, 14, 148-164.

Rice, R. W., Gentile, D. A., \& McFarlin, D. B. (1991). Facet importance and job satisfaction. Journal of Applied Psychology, 76, 31-39.

Rice, R. W., McFarlin, D. B., \& Bennett, D. E. (1989). Standards of comparison and job satisfaction. Journal of Applied Psychology, 74, 591-598.

Rich, B. L., Lepine, J. A., \& Crawford, E.R. (2010). Job engagement: Antecedents and effects on job performance. Academy of Management Journal, 53, 617-635.

Rogelberg, S. G., Leach, D. J., Warr, P. B., \& Burnfield, J. (2006). "Not another meeting!" Are meeting time demands related to employee well-being? Journal of Applied Psychology, 91, 83-96. 
Russell, J.A. (2003). Core affect and the psychological construction of emotion. Psychological Review, 110, 145-172.

Schaufeli, W. B., Bakker, A. B., \& Salanova, M. (2006). The measurement of work engagement with a short questionnaire: A cross-national study. Educational and Psychological Measurement, 66, 701-716.

Schmidt, F. L., \& Hunter, J. E. (1989). Interrater reliability coefficients cannot be computed when only one stimulus is rated. Journal of Applied Psychology, 74, 368-370.

Schneider, B., Salvaggio, A. N., \& Subirats, M. (2002). Climate strength: A new direction for climate research. Journal of Applied Psychology, 87, 220-229.

Schwartz, S. H. (1992). Universals in the content and structure of values: Theoretical advances and empirical tests in 20 countries. Advances in Experimental Social Psychology, 25, 1-65.

Schwartz, S. H. (1999). A theory of cultural values and some implications for work. Applied Psychology: An International Review, 48, 23-47.

Sims, H. P., \& Szilagyi, A. D. (1976). Job characteristic relationships: Individual and structural moderators. Organizational Behavior and Human Performance, 17, 211 230.

Tiegs, R. B., Tetrich, L. E., \& Fried, Y. (1992). Growth need strength and context satisfactions as moderators of the relations of the job characteristics model. Journal of Management, 1992, 18, 575-593.

Ungemah, J. M. (2010). Establishing and maintaining employee motivation from recruitment through induction, transition, and retirement. (Unpublished doctoral dissertation). London: London Metropolitan University.

Van den Broeck, A., Van Ruysseveldt, J., Smulders, P., \& De Witte, H. (2011). Does an intrinsic work value orientation strengthen the impact of job demands? A perspective from the Job Demands-Resources Model. European Journal of Work and Organizational Psychology, 20, 581-609.

Viswesvaran, C., Sanchez, J. I., \& Fisher, J. (1998). The role of social support in the process of work stress: A meta-analysis. Journal of Vocational Behavior, 54, 314-334.

Vroom, V. H. (1959). Some personality determinants of the effects of participation. Journal of Abnormal and Social Psychology, 59, 322-327.

Wanous, J. P., Reichers, A. E., \& Hudy, M. J. (1997). Overall job satisfaction: How good are single-item measures? Journal of Applied Psychology, 82, 247-252.

Warr, P. B. (2007). Work, happiness, and unhappiness. Mahwah, NJ: Erlbaum.

Warr, P. B. (2008). Work values: Some demographic and cultural correlates. Journal of Occupational and Organizational Psychology, 81, 751-775. 
Warr, P. B. (2013). Jobs and job-holders: Two sources of happiness and unhappiness. In S. A. David, I. Boniwell, and A. Ayers (Eds.), Oxford handbook of happiness (pp.733-750). Oxford and New York: Oxford University Press.

Warr, P. B., Bindl, U., Parker, S., \& Inceoglu, I. (2013). Four-quadrant investigation of jobrelated affects and behaviours. European Journal of Work and Organisational Psychology, in press.

Warr, P. B., \& Inceoglu, I. (2012). Job engagement, job satisfaction, and contrasting associations with person-job fit. Journal of Occupational Health Psychology, 17, 129-138. 
TABLE 1

Perceived actual job features (AJF) and wanted job features (WJF): Factor-level descriptive statistics for the three studies

\begin{tabular}{|c|c|c|c|c|c|}
\hline \multirow[t]{2}{*}{ Job factor } & \multirow[t]{2}{*}{ Study } & \multicolumn{2}{|c|}{$\begin{array}{l}\text { Actual job factor } \\
\text { (AJF) }\end{array}$} & \multicolumn{2}{|c|}{$\begin{array}{c}\text { Wanted job factor } \\
\text { (WJF) }\end{array}$} \\
\hline & & Mean & $\begin{array}{l}\text { Standard } \\
\text { deviation }\end{array}$ & Mean & $\begin{array}{l}\text { Standard } \\
\text { deviation }\end{array}$ \\
\hline \multirow{3}{*}{$\begin{array}{l}\text { 1. Supportive } \\
\text { environment }\end{array}$} & 1 & $\begin{array}{l}5.48 \\
\end{array}$ & 1.61 & 7.14 & 0.89 \\
\hline & 2 & 5.46 & 1.31 & 6.83 & 0.98 \\
\hline & 3 & 5.46 & 1.24 & 6.67 & 1.00 \\
\hline \multirow{3}{*}{$\begin{array}{l}\text { 2. Competition and } \\
\text { financial focus }\end{array}$} & 1 & 4.67 & 1.65 & 5.83 & 1.51 \\
\hline & 2 & 4.75 & 1.86 & 5.94 & 1.42 \\
\hline & 3 & 4.76 & 1.75 & 5.88 & 1.32 \\
\hline \multirow{3}{*}{$\begin{array}{l}\text { 3. Personal } \\
\text { influence }\end{array}$} & 1 & 5.10 & 1.66 & 7.10 & 1.10 \\
\hline & 2 & 5.24 & 1.67 & 6.90 & 1.08 \\
\hline & 3 & 5.43 & 1.61 & 6.92 & 1.04 \\
\hline \multirow{3}{*}{$\begin{array}{l}\text { 4. Challenging } \\
\text { workload }\end{array}$} & 1 & 5.90 & 1.36 & 6.58 & 0.96 \\
\hline & 2 & 6.10 & 1.47 & 6.58 & 0.98 \\
\hline & 3 & 6.11 & 1.36 & 6.59 & 0.91 \\
\hline \multirow{3}{*}{$\begin{array}{l}\text { 5. Ethical } \\
\text { principles }\end{array}$} & 1 & 5.94 & 1.39 & 7.41 & 1.03 \\
\hline & 2 & 5.73 & 1.51 & 7.25 & 1.05 \\
\hline & 3 & 5.97 & 1.47 & 7.27 & 1.03 \\
\hline \multirow{3}{*}{ 6. Career progress } & 1 & 4.74 & 1.62 & 7.57 & 0.97 \\
\hline & 2 & 4.70 & 1.77 & 7.32 & 1.10 \\
\hline & 3 & 4.45 & 1.66 & 7.04 & 1.19 \\
\hline \multirow{3}{*}{$\begin{array}{l}\text { 7. Amount of } \\
\text { social contact }\end{array}$} & 1 & 6.17 & 1.58 & 7.19 & 1.20 \\
\hline & 2 & 6.31 & 1.59 & 7.06 & 1.18 \\
\hline & 3 & 6.55 & 1.59 & 7.04 & 1.11 \\
\hline \multirow{3}{*}{$\begin{array}{l}\text { 8. Status and } \\
\text { responsibility }\end{array}$} & 1 & 4.86 & 1.87 & 6.72 & 1.37 \\
\hline & 2 & 4.96 & 2.06 & 6.58 & 1.35 \\
\hline & 3 & 4.91 & 2.03 & 6.46 & 1.32 \\
\hline \multirow{3}{*}{ All-factor mean } & 1 & 5.36 & 1.60 & 6.95 & 1.12 \\
\hline & 2 & 5.41 & 1.65 & 6.81 & 1.14 \\
\hline & 3 & 5.45 & 1.59 & 6.73 & 1.12 \\
\hline
\end{tabular}

Note:

$N$ 's $=1001,840$ and 4217 for Studies 1, 2 and 3 respectively. 